\title{
POTENTIAL IMPACTS OF CLIMATE CHANGE ON MONGOLIA'S PLANT PROTECTION STATUS QUO
}

\section{Review paper}

\author{
B.Batkhuyag ${ }^{1}$, Kh.Batnaran ${ }^{2 *}$
}

${ }^{1}$ WWF Mongolia Programme Office, Ulaanbaatar, Mongolia

${ }^{2}$ Plant Protection Research Institute, Mongolian University of Life Sciences, Ulaanbaatar, Mongolia

*Corresponding author: batnarano@yahoo.com

\begin{abstract}
Mongolia's 2030 Sustainable Development Vision set a goal to be a self-sufficient in grain, potatoes and vegetables by 2030. However, Mongolia's pastoral animal husbandry and rain-fed agriculture are extremely sensitive to climate change. The Asian migratory locust is considered as the most harmful grasshopper in the world. Until 1970 th these locust's distribution areas in Mongolia were confined to oasis of Gobi deserts. A study on Asian migratory locust in Russia predicts distribution and formation of new permanent habitats of the locust in Chita oblast, Krasnoyarsk territory and Republic of Tyva. The Colorado beetle is one of the world's most infamous invasive species due to its rapid adaptation to a wide range of ecological conditions and ability to disperse long distances. The climate modeling of Colorado beetle showed that with current trend, the beetle will expand its distribution into the most eastern and north-eastern regions of the Russian Federation. In China, the Colorado beetle was first detected in Xinjiang in 1993 and subsequently spread eastward. In China the Colorado beetle is currently expanding its areas at rate of $25 \mathrm{kms}$ year (12-45 kms/year). Both species' distribution patterns in neighboring countries show eventual establishment of permanent habitats around Mongolia. Their invasion to Mongolia will threaten country's food security due to direct destruction of cereal and potato crops, and increased application of highly toxic pesticides. In light of these threats, Mongolia should start taking serious preventive measures by increasing surveillance and dedicated risk assessment studies for potential agricultural pests and diseases.
\end{abstract}

KEY WORDS: Mongolia, Climate Change, Migratory locust, Colorado beetle, plant protection.

\section{INTRODUCTION}

As of 2016 Mongolia had sown 505.3 thousand hectares of areas, of which $74.8 \%$ was under cereal field and $3 \%$ was under potatoes. The Central region of Mongolia gave $72.2 \%$ of the all grain harvest, followed by Khangai region (21.0\%), Eastern region $(4.9 \%)$ and Western region with $1.9 \%$ of total harvest. In case of potato harvest, the central region produced $69.9 \%$, the khangai region produced 13.2 , the west produced $11.0 \%$, and the eastern region produced $4.9 \%$ [1]. Thus the extreme continental climate, with long cold winters and low precipitation, is considered as one of the key factors to agricultural production in Mongolia. The crop yield in any given area can fluctuate up to $50 \%$ due weather conditions of given year and season and it can even be lost altogether. In addition, the arable soils of Mongolia comprise dark chestnut and chestnut soils, which are typical of soils that evolved with steppe vegetation. These soils are inherently fertile but shallow soils, with an average depth of $30 \mathrm{~cm}$. Because of their light texture, moisture retention is low and the soils are susceptible to erosion. Mongolia's fragile ecosystems, pastoral animal husbandry and rain-fed agriculture are extremely sensitive to climate change. Mongolian ecosystems have already altered over the past forty years due the impacts of climate change. These 
changes were prominently expressed through increased desertification, water supply shortages and frequenting natural disasters that led to financial, environmental and human losses [2]. The "Mongolia Assessment Report on Climate Change 2009" [3] published by the Ministry of Environment, Nature and Tourism of Mongolia had shown that due to climate change impacts the winter in Mongolia will become milder and snowy and there is high probability of climate anomalous phenomena like harsh winter, heavy snow etc. The assessment also predicts that summer will become drier due to high evaporation due to increase in average temperature coupled with small increase in summer precipitation. The report also indicates that by 2080 , forest-steppe zone, where the main crop farming is practiced, is likely to turn into steppe. In turn, the steppe zone is likely to be pushed by the semi-desert zone (Gobi) from the south and decrease significantly. As a result, by 2080 , the two areas of most productive ecosystems - forest-steppe and steppe areas, sandwiched between taiga forest and semi-desert, will decrease due to a lack of rainfall and an increase in temperature in the warm season. Although Mongolia has established a network of agro-meteorological stations since 1959, not much has been done to determine and develop adaptation measures for crop farming sector. Even less was done with regards to impacts of climate change to agricultural pests and plant diseases despite the alarming records both in Mongolia and neighboring countries. Considering the fact that "Mongolia's Sustainable Development Vision 2030" [4] set a goal to be a self-sufficient in grain, potatoes and vegetables by 2030, this paper will focus on two most infamous pest of the world that could have serious consequences to agricultural sector in Mongolia. As an adaptation to the climate change, the "Mongolia's 2030 Sustainable Development Vision" also stated that by 2030 Mongolia will increase its irrigated crop field up 120 thousand hectares doubling current 54 thousand hectares of irrigated crop field, of which less than 20 percent fall under cereals. Asian migratory locust (Locusta migratoria migratoria L.) is considered as the most harmful grasshopper species and its areas of distribution comprises practically all temperate and tropical part of eastern hemisphere (Figure 1), i.e. Europe, Africa, Arabian and IndoPakistan peninsulas, Caucasus, Central and Southeastern Asia, Australia and New Zealand where over dozen known subspecies of L. migratoria L. cause severe damage to crops and fodder, notably to the gramineous plants $[5,6,7,8]$.

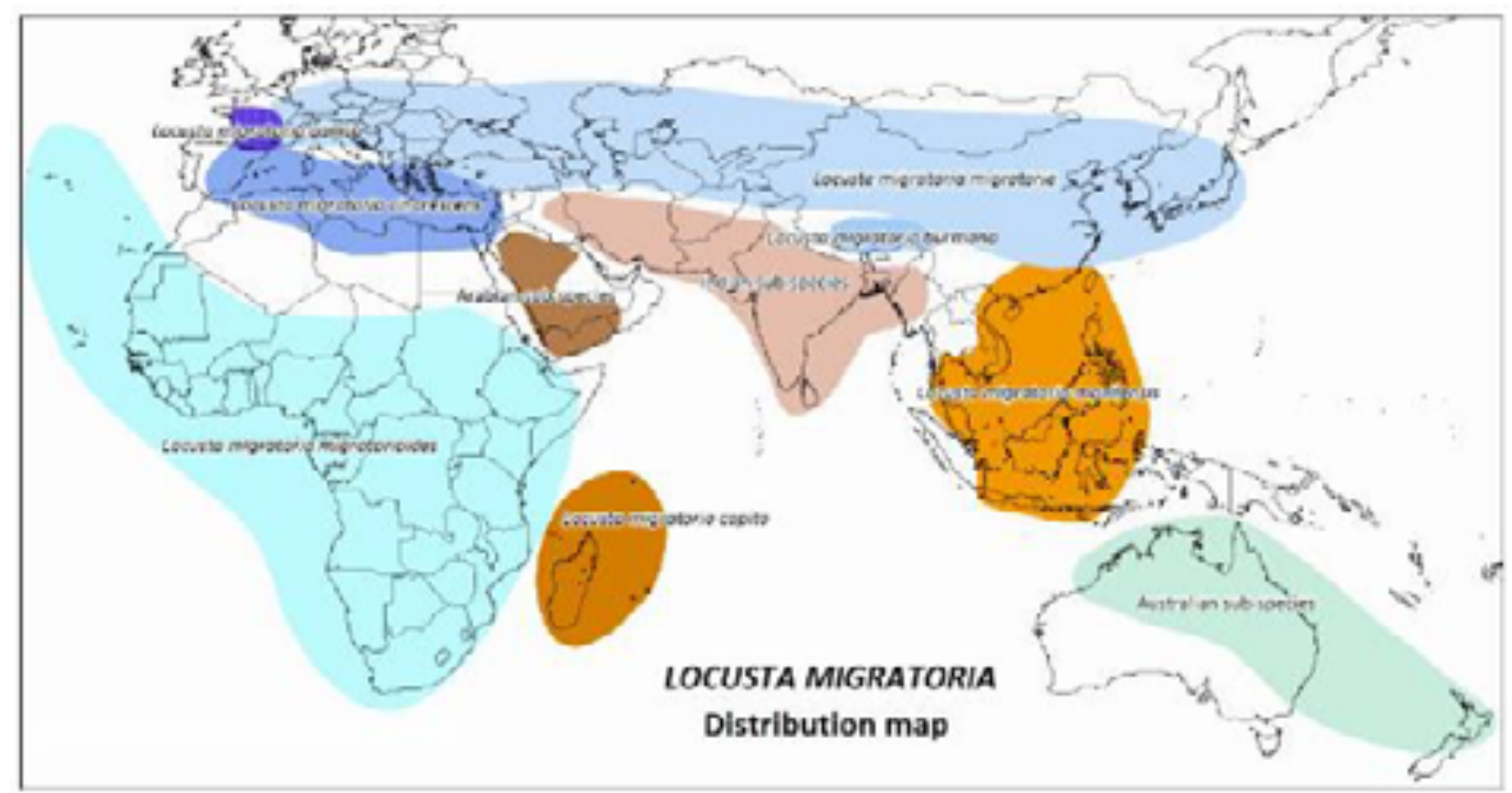

Figure 1. Migratory locust (Locust migratoria L.) distribution map (Source: www.fao.org) 
In Palearctic zone, the distribution of Asian migratory locust does not go beyond north of $55^{\text {th }}$ latitude and its main distribution and outbreak area are located between 40-48 degree of north latitude. The seven known permanent habitats in Russia and Central Asian countries are all tied to lakes and river floodplains where the locusts mainly feed on reed and couch grasses $[6,9]$. The Russian scientists estimate that locust outbreak probability in Russian territory will only increase in $21^{\text {st }}$ century due to climatic factors that would lengthen the outbreak periods and shorten the depression time between the outbreak periods. The study also predicts that distribution and formation of new permanent habitats of Asian migratory locust in regions such as Chita oblast, Krasnoyarsk territory and Republic of Tyva adjacent to Mongolia [10]. In China, Asian migratory locust is represented by three subspecies, with L.migratoria migratoria L. distributed most widely covering whole central eastern and western regions, $L$. migratoria manilensis Meyen occupying the subtropical south eastern part and L.migratoria tibetensis Chen occupying the highlands of Tibetan Plateau and adjust areas. Outbreaks in China historically occurred every ten years, usually after dry summers followed by warm winter. The swarms in Chine mostly restricted the river valleys such as delta areas of the Yellow River that floods intermittently. The studies carried out by Chinese researchers revealed that different populations of the $\mathrm{L}$. migratoria in China exhibit strong local adaptability. The eggs of migratory locust from the temperate zone has showed much more cold hardiness than the southern populations, showing evolutionary adaptability to local thermal environment [11]. Moreover, recently commissioned study on impacts of climate change to L. migratoria tibetensis Chen in the Qinghai-Tibet High Plateau showed that since 1990s, L. m.tibetensis has been on arise and during outbreaks in 2003 to 2006 locusts density reached 1000 to 3000 individuals per $\mathrm{m} 2$ threatening the production of highland barley and grass. The study also showed that there is a significant correlation between increasing of potential distribution area and global warming and annual surface temperature increase at the speed of $0.0301{ }^{\circ} \mathrm{C}$ triggers expansion of distribution area by $504.38 \mathrm{~km} 2$ per year [12]. In 2011, the field expedition led by Dr. Batnaran revealed a distribution of Asian migratory locust (Locusta migratoria migratoria L.) in Uvs lake basin of Western Mongolia [13,14]. Up to 1970's these locust's distribution areas in Mongolia were all confined to oasis of Gobi deserts south of Altai mountain range $[15,16,17,18,19,20]$. This new distribution range pushes the boundaries former area of distribution by $500 \mathrm{kms}$ northwards [21]. While the distribution areas are still tied with the lakes and other surface water, the early distribution areas belonged, in accordance with B. Jambaajamts (1989) to the moderately cold region of sharp dry-warm zone with sum of above active air temperature above 2500 degrees, while the recent distribution area of Uvs lake basin is considered as a severe cold region of sharp dry-warm zone with sum of active temperature ranged between 2000-2500 degrees [22]. However, the Government planned expansion of irrigated farming, especially the irrigated wheat and other grain fields located in warmer lowlands valleys of Mongolia will undoubtedly attract the Asian migratory locust and expand its expanding habitats. Unless appropriate measures such as regular monitoring and timely control measures are not taken this will jeopardize Mongolia's food safety both in terms of grain production and public health safety due to excessive pesticide residues in food and its soil and water contaminations.

\section{Second pest of special concern is potential invasion of Colorado beetle (Leptinotarsa decemlineata} Say).

The Colorado beetle is native to Mexico, where its main host plants are Solanum elaeagnifolium Cav. and $S$. buffalobur (Solanum rostratum Dunal) from family Solanaceae, two wild plant species. The Colorado beetle is most harmful to potato and eggplant, damaging tomato to a lesser extent. The pest is potentially dangerous for red sweet and hot pepper, strawberry, tobacco, and some other solanaceous cultures $[23,24]$. Currently the eastern border of the Colorado beetle distribution in Russian Federation already passed European part of the Russia and permanent populations of the Colorado beetle on the territory of Siberia has reached the southern regions of the Krasnoyarsk Territory. In the natural environment, the permanent distributions habitat of Colorado beetle is limited by abiotic factor, i.e., it needs at least 60 days of above +15 degree days 
during warm season and winter soil temperature above -8 degree at $20 \mathrm{~cm}$ depth. Yet, in Russia the distribution of Colorado beetle has significantly advanced northwards and spread in areas like south of Karelia, the Arkhangelsk region, the Komi Republic - up to $62-63^{\circ} \mathrm{N}$, where the beetle's acclimatization was previously considered impossible. The recent findings of new distribution areal in northern and Eastern Russia showed two mutually reinforcing factors that allowing the beetle penetrate deeply in areas with harsh winters: i) genetic adaptation to cold areas beetle that could already be differentiated by the marking on the pronotum of the beetle, and; ii) behavioral change of that allow the Colorado beetle survive winter in human created shelters such as storage, basements of infrastructures close to potato growing areas [25]. The climate modeling of Colorado beetle distribution in Russia and its neighboring country showed that if the current trend in climate change continues, the Colorado beetle will continue its advance into the eastern and north-eastern regions of the Russian Federation (Figure 2) including the Russian Far East, and the southern part of Sakhalin Island [26].

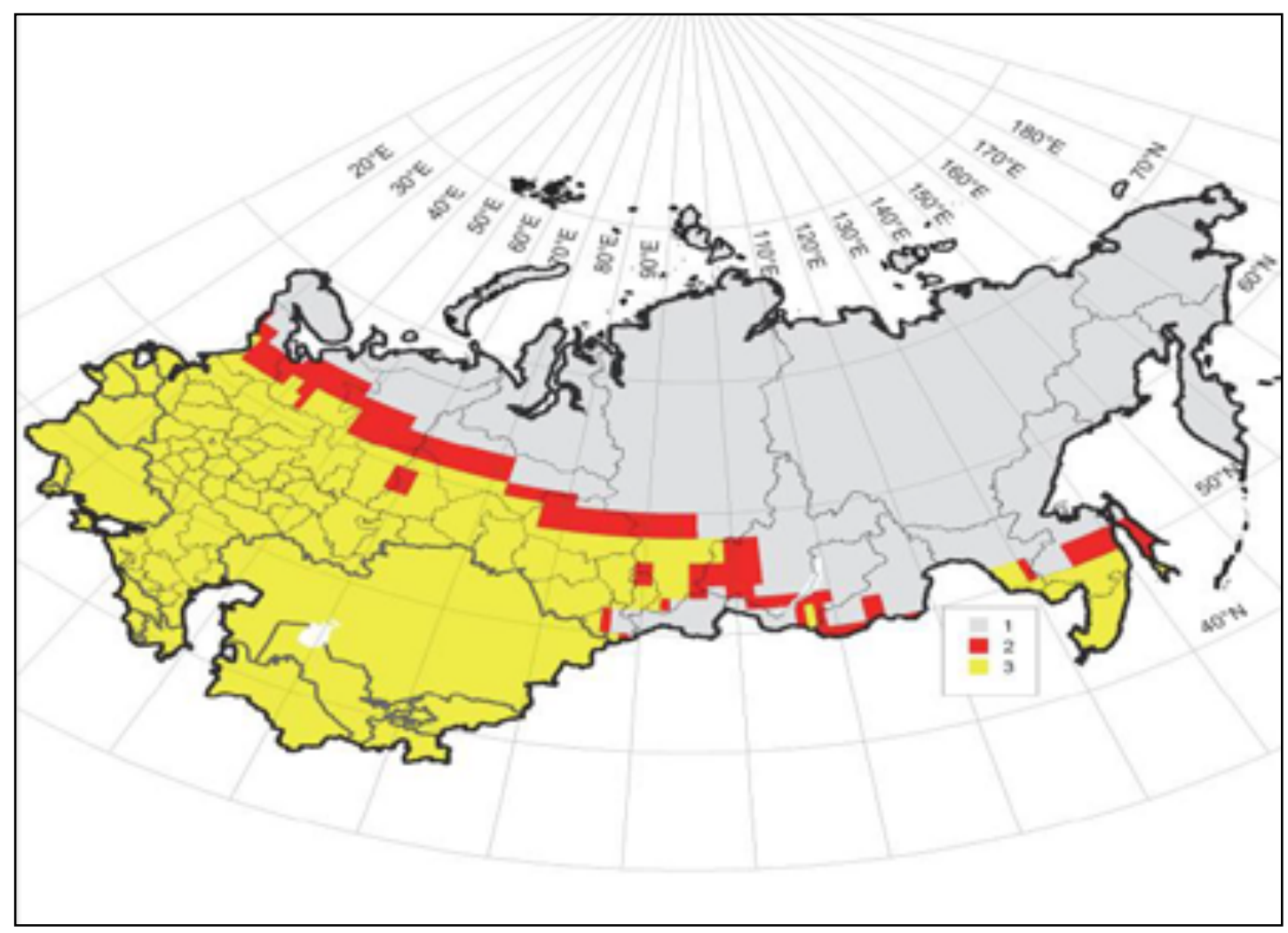

Figure 2. Potential change in the climatic range of Colorado Beetle in (Leptinotarsa decemlineata Say) the territory of Russia and neighboring Countries in 2031-2050 in comparison with 1991-2010. (Source E.N. Popova, I.O Popov [27])

1 - the territory outside the boundaries of the climatic area in both period;

2 - Additional territory of invasion due to climate change in 2031-2050 years compared to 1991-2010;

3 - The territory under invasion in both periods of time under current trends of climate change.

In China, the Colorado beetle was first detected in Xinjiang in 1993 and subsequently spread eastward. As of 2010, the beetle had invaded 38 counties and cities in China, with a distribution area of 277000 $\mathrm{km} 2$, between $42^{\circ} 40^{\prime}-48^{\circ} 28^{\prime} \mathrm{N}$ and $80^{\circ} 15^{\prime}-90^{\circ} 41^{\prime} \mathrm{E}$.
The distribution area could be divided into four zones (Figure 3), namely, Ili River Valley, northern slope of the Tianshan Mountains, Tacheng Basin, and Altay. In these four regions the Colorado beetle is expanding its areas at rate of $25 \mathrm{~km} /$ year $(12-45 \mathrm{~km} /$ year). 


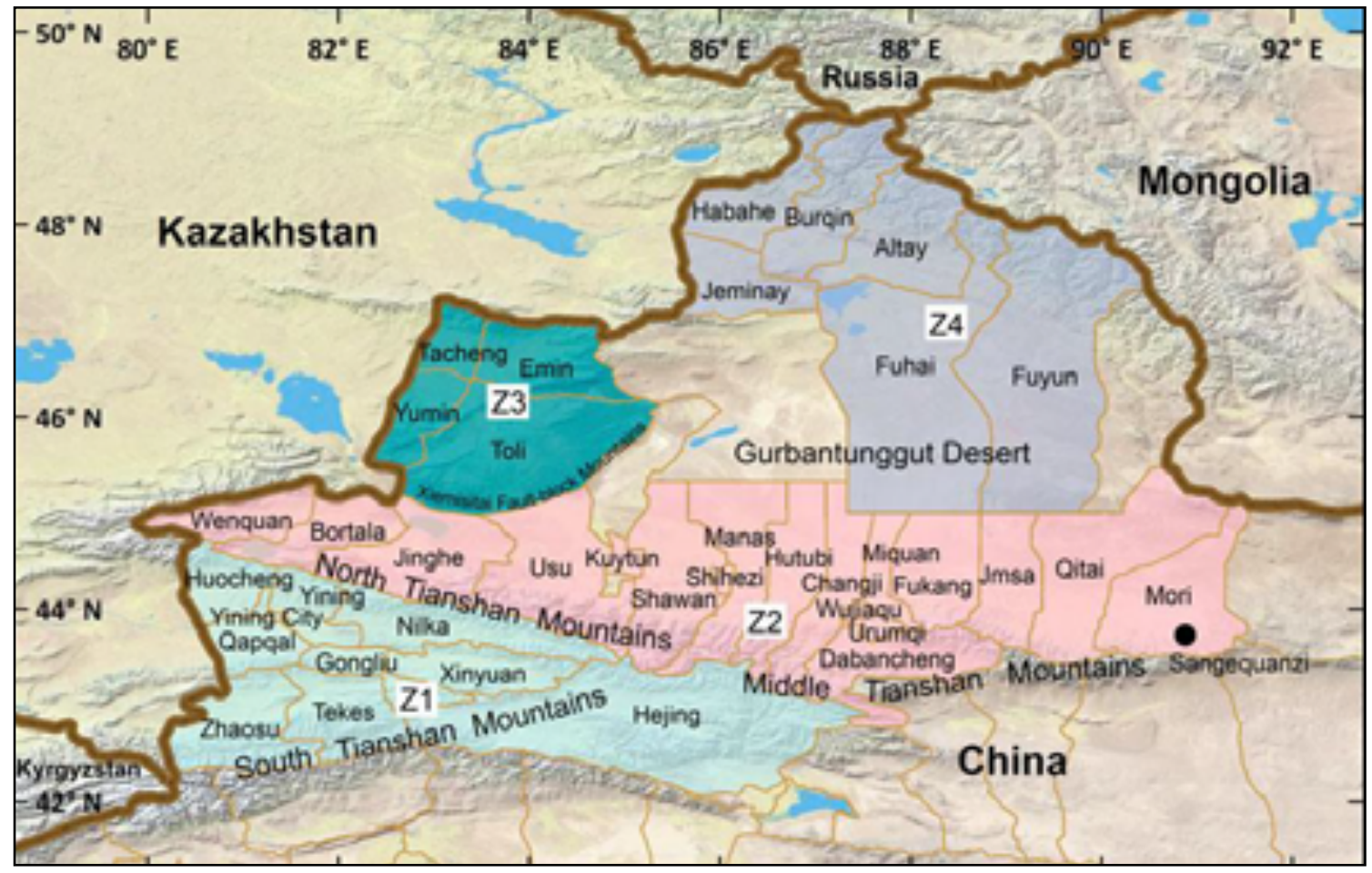

Figure 3. Map of current (up to 2010) distribution of Colorado potato beetle in China.

(Source: Ning Liu et al. [28]) Z1. Ili River Valley, Z2. Northern slope of the Tianshan Mountains, Z3.

Tacheng Basin, Z4. Altay

In China, the Colorado beetle caused serious damage to potato and eggplant production, in some potato fields, the crop loss exceeds $50 \%$ and occasionally reaches $100 \%$ with zero yield. The current annual economic loss caused by the Colorado beetle in China is estimated to be 3.2 million USD. It is also estimated if the beetle invades the whole country the potential annual economic losses could reach as high as 235 million USD [27].

The Colorado beetle's current distribution show that it had already reached the western borders of Mongolia and will eventually pincer Mongolia both from south and north. Considering the fact that the Colorado beetle has already adapted and formed permanent habitats in the climatic zones neighboring to Mongolia, a grim conclusion of Colorado beetle's invasion in near future is inevitable. Moreover, the climate change scenarios that predict milder winter with increased precipitation (2) also implies that in the future at least in some areas soil freezing depth will be shallower, and thus, a formation of permanent habitats tied with wild and cultivated Solanaceae is very possible once Colorado beetle enter into the territory. Mongolia's flora includes 9 plants belonging to family Solanaceae that grow in wild and 5 of these plants also grow as ruderal plants in and around abandoned crop fields, irrigation channels and human settlement [28]. If Colorado beetle enters into Mongolia, these wild plants could serve as a host plant for rapid dissemination channels in parallel to anthropogenic factors for mechanical dissemination. Both Migratory locust and Colorado beetle will threaten Mongolia's food security i) in terms of availability due to direct destruction of cereal and potato crops, and; ii) quality due to increased application of highly toxic pesticides. In light of the potential increase of pasture and crop pests and diseases induced by climate change and already increased frequencies of cross border travel, Mongolia should start taking serious steps for preventive measures by increasing surveillance and dedicated risk assessment studies for potential agricultural pests and diseases. 


\section{REFERENCES}

[1] National Statistical Office of Mongolia. www.1212.mn. National Statistical office of Mongolia. [Online] NSO, 2018.

[2] Anand Prathivadi Bhayankaram, "From Vulnerability to Sustainability: Environment and Human Development" $5^{\text {th }}$ Mongolian Human Development Report, Ulaanbaatar: Admon, 2011

[3] D. Dagvadorj; L. Natsagdorj, J. Dorjpurev, B. Namkhainyam. Mongolia Assessment Report on Climate Change 2009. Ulaanbaatar: Ministry of Environment, Nature and Tourism, Mongolia, 2009. ISBN 978-99929-934-3-X.

[4] "Mongolia Sustainable Development Vision 2030" (Unauthorized translation from Mongolian), The Secretariat of the State Great Hural of Mongolia, Ulaanbaatar, 2016

[5] FAO. Locust watch. Food and Agriculture organization of UN. [Online] http://www.fao.org/ag/locusts-CCA/en/.

[6] Research, Centre for Overseas Pest. The locust and grasshopper agricultural manual. London: Centre for Overseas Pest Research , 1982. ISBN: 0851351204.

[7] G. B. Popov, Nymphs of the Sahelian Grasshoppers, Chatham, Kent: ODNRI, 1989

[8] Zheng Zheming and Xia Kailing "Orthoptera Acridiodae Oedipodidae and Arcypteridae" in FAUNA SINICA. INSECTA, vol. 10, Beijing: Science Press, 1998

[9] G, Ya. Bei-Bienko, L.L. Mistshenko, Locust and Grasshoppers of USSR, vol. 2, MosvowLeningrad: USSR Academy Printing, 1951 (In Rus.)

[10] E. N Popova, I. O. Popov, "Harmful locusts of south Russia and climatic factors affecting their reproduction and distribution" in Problems of ecological monitoring and ecosystem modeling, vol. XXII, Moscow: IGCE, pp. 124-147, 2009, (In Rus.)

[11] Differences in egg thermotolerance between tropical and temperate populations of the migratory locust Locusta migratoria (Orthoptera: Acridiidae). Xian-Hui Wang, Le Kang. s.1. : Journal of Insect Physiology, 2005, Vols. 51 (2005) 1277-1285.
[12] Xiongbing Tu, Zhihong Li, Zehua Zhang, Zhigang $\mathrm{Wu}$, Wenlong $\mathrm{Ni}$, Liao $\mathrm{Fu}$, and Yasen shali. The Potential Geographical Distribution of Locusta Migratoria Tibetensis Chen (Orthoptera: Acrididae) in Qinghai-Tibet Plateau. CCTA 2012. 2013, Vols. Part 2 pp. 343-351.

[13] Kh. Batnaran, "Pastureland, fodder and crop pest grasshoppers and locust of Mongolia" Ulaanbaatar, 2015, pp. 66-67 (In Mongolian)

[14] Kh Batnaran, T. Turbat "The results of the Asian migratory locust (Locusta migratoria migratoria Linnaeus, 1758) research" in Central Asian Ecosystem: Research, conservation and sustainable use, "Uvs Lake" 12th International Symposium, Ulaangom, 2014 (In Mongolian)

[15] L. Chogsomzhav, "Acridoidea and Tettigonioidea of the Mongolian People's Republic" in Insects of Mongolia, vol 1. Leningrad: Nauka,1972, pp. 151-198 (In Rus.)

[16] L. Chogsomzhav, "On the problem of the zoogeography of the Mongolian Great Lake's Depression and Gobi" in Insects of Mongolia, vol. 2. Leningrad: Nauka,1974, pp. 10-13 (In Rus.)

[17] L. Chogsomzhav, "Orthopteroidea of the West and South Mongolia" in Insects of Mongolia, vol. 2. Leningrad: Nauka,1974, pp. 23-33 (In Rus.)

[18] L. Chogsomzhav, "Orthopteroidea of the Gobi Desert" in Insects of Mongolia, vol. 5. Leningrad: Nauka,1977, pp. 83-92 (In Rus.)

[19] L. Chogsomzhav, "Review of literature on Orthopteroidea of the Mongolian People's Republic" in Insects of Mongolia, vol. 10. Leningrad: Nauka,1989, pp. 79-83 (In Rus.)

[20] L. Chogsomzhav, "Composition and distribution of fauna of the Orthopteroidea in the Mongolian People's Republic" in Insects of Mongolia, vol. 10. Leningrad: Nauka,1989, pp. 84-96 (In Rus.)

[21] Kh.Batnaran, B.Batkhuyag, "Impacts of climate change on grasshopper distribution in Mongolia", International conference on 
Central Asian plant biodiversity and ecosystem service, Ulaanbaatar, 2013 (In Mongolian).

[22] Kh.Batnaran, B.Batkhuyag, Climate change and anthropogenic impacts on grasshopper distribution in Mongolia, 11th International Cogress of Orthopterology, Kunming, 2013.

[23] H.H. Ross,C.A. Ross and June R.P. Ross, $A$ textbook of Entomology, Moscow: Mir, 1985 (In Rus.)

[24] A.A. Migulin, G.E. Osmolovskii, B.M. Litvinov et al., Agricultural Entomology, Moscow: Kolos (In Rus.)

[25] N.V. Ryabova, "Impacts of ecological factors on the structure and dynamics of Colorado beetle numbers in Kemerova oblast" $\mathrm{Ph}$. D. dissertation, Tumen University, Russian Federation, 2011
[26] E. N. Popova, I.O. Popov, "Climatic factors limiting agricultural pests and diseases areas and assessment methodology for areas under climate change" in Problems of ecological monitoring and ecosystem modeling, Moscow: IGCE, 2011

[27] Ning Liu, Yingchao Li \& Runzhi Zhang, Invasion of Colorado potato beetle, Leptinotarsa decemlineata, in China: dispersal, occurrence, and economic impact, Entomologia Experimentalis et Applicata, 2012.

[28] Grubov, Key book for vascular plant of Mongolia, Ulaanbaatar, Gan print, 2008. (In Mongolian) 